\title{
An Analysis Of The Techniques Of Technology Transfer
}

Jack Fuller, West Virginia University, USA

Christopher Hohman, Consultant, USA

\begin{abstract}
Technology transfer is an increasingly popular topic in today's ultra competitive business environment. This popularity can be attributed to the fact that if utilized properly, it can not only strengthen a firm's competitive advantage, but can also bolster the economy of a region or even country. Technology transfer is also advantageous to the academic's world, as professors can gain funding for their research efforts and prestige for a university if they are able to have their technologies adopted by a business. This paper condenses a vast wealth of information on technology transfer into an easy to read compact format. It will first outline the reasons that technology transfer is not as widely used as it should be. Methods which academics and business professionals can use to enhance the possibility that technology transfer will occur will then be discussed.
\end{abstract}

\section{INTRODUCTION}

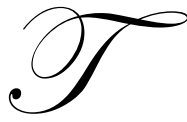

echnology transfer is an increasingly popular topic in today's ultra competitive business environment. This popularity can be attributed to the fact that if utilized properly, it can not only strengthen a firm's competitive advantage, but can also bolster the economy of a region or even country. Technology transfer is also advantageous to the academic's world, as professors can gain funding for their research efforts and prestige for a university if they are able to have their technologies adopted by a business (Reisman, 2005).

Due to the popularity of the topic, numerous academic research articles have been published on technology transfer. Its popularity and importance are so great that the Journal of Technology Transfer was created solely for the publication of technology transfer related research. Many insightful and potentially advantageous articles have been researched and published in the Journal of Technology Ttransfer and other journals. However, finding relevant information about how to enhance the prospects of successful technology transfer may be a daunting task because of the technical nature of academic writing and the fact that researchers from a diverse number of academic fields research technology transfer (Reisman, 2005).

This paper hopes to lessen the task by condensing a vast wealth of information on technology transfer into an easy to read compact format. The following will first outline the reasons that technology transfer is not as widely used as it should be. It will be followed by methods which academics and business professionals can use to enhance the possibility that technology transfer will occur (Reisman, 2005).

Before continuing, it is important to keep in mind several pieces of information. First, technology transfer has been defined a number of ways by academics in many different fields. However, for the purposes of this paper, technology transfer is defined as the dissemination of technological innovations from a provider (an academic) to a recipient (a firm). Second, many of the studies highlighted in the following pages were not the result of energy industry research. Despite this, this article is readily adaptable to technology transfer in the energy industry, as the research almost completely was conducted in a technical field, such as engineering. With these facts in mind, the following will highlight reasons that technology transfer is not more prevalent from the academic world to the industrial world. This will be followed by methods which both academics and industry professionals can use to enhance the prospects of successful technology transfer (Reisman, 2005). 


\section{WHY TECHNOLOGY TRANSFER IS NOT MORE PREVALENT}

Perhaps the largest reason for a lack of technology transfer from universities to industry is the mind set of academics. Academics are conditioned to view their main professional objective as simply producing academic papers to be published in their field's major journals. This can only be expected, as the university system is established to reward publications and the basic research that contributes to them (Bozeman, 2000).

The university system of "publish first" has contributed to the view that technology transfer to the industrial sector is a trivial objective in an academic's career. As a result, only $23 \%$ of university laboratories see technology transfer as a major mission and only $40 \%$ of university laboratories are actually involved with technology transfers of any kind (Bozeman, 2000).

The mindset of conducting basic research in order to be published has also made academics weary of partnering with firm's to develop technology. A study conducted in 1996 showed that many professors are hesitant to partner with industries to develop technology as such a partnership would require the academic to potentially work in a different way than he/she is accustomed to. Academics are fearful that they would have to make changes which would hurt their academic credibility and ultimately diminish their publishing prospects if they partner with industries (Bozeman, 2000).

Another factor discouraging technology transfer is the assumption by academics that their research efforts are only sought after by firms as a cost effective alternative to discovering technologies in house. This assumption has led to many academics questioning whether research that leads to technology transfer is challenging and intellectually thought provoking enough to be used as the basis for articles in peer reviewed journals (Lee, 1996).

The academic mindset is apparent to those in industry, because professors educated nearly all industry leaders. This projected academic mindset causes industry leaders to be hesitant to partner with academics, as they are well aware of a professors propensity for placing basic research above all else. Also, studies have shown that academic technology transfers generally result in a low yield in exchange for a high risk by the firm sponsoring it. Therefore, many industry insiders would be hesitant to partner with academics, as their track record for producing profitable technology transfers is less than stellar (Bozeman, 2000). Methods must be devised to break away from the mindset of business leaders and professors that hinder and in some cases stop technology transfer efforts. The following sections will examine some strategies to achieve this.

\section{REASSURING THE BUSINESS WORLD}

As mentioned above, businesses are often reluctant to engage in technology transfer projects because they believe their investment will not yield financial gains. It is true that many technology transfers will not immediately yield major benefits to the company that pursues them. This does not mean these transfers are not potentially valuable to a firm in the long run. Technology transfers that appear on the surface to be of little value can be built upon by firms to ultimately discover technology breakthroughs that give a firm competitive advantage in the long run. Firms should therefore consider a technology's potential value if it can be further developed in the future to obtain a cost saving breakthrough (Bozeman, 2000).

In addition to reminding businesses that technology is often built upon to achieve a competitive advantage yielding breakthrough, academics can also ensure businesses that they are attempting to develop commercially viable technologies by agreeing upon effectiveness criteria before entering into a partnership. There are several effectiveness criterions that are commonly used in technology transfer collaborations.

One commonly used metric is the market impact criteria. This criterion is a straight forward measure that judges the success of technology transfer on the financial impact an innovation had on the firm's bottom line. This metric is likely the most reassuring to apprehensive firms as it measures success simply by their financial gain (Bozeman, 2000). 
Another strategic criterion which could be used to measure technology transfer is the economic development criterion. The economic development criterion gauges success in technology transfer by the economic development that was achieved in the region due to the innovation. This metric may be less desirable to firms as it only indirectly measures their financial gain from a transfer (Bozeman, 2000). It may be a desirable metric, however, for a university as it measures the positive impact an innovation had on creating employment in a region. This is advantageous to universities as they often include regional economic development as one of their missions.

The metrics mentioned above are both effective ways to assure firms that academic researchers have financial impact in mind when they design technology. However, if a firm is seeking to use technology to comply with government policy, they may want to agree upon using the political criteria to gauge success. The political effectiveness criteria measures success of a collaboration based upon whether or not it achieved an agreed upon political goal (Bozeman, 2000). Although this metric will not take a firm's financial gains into account, it may be desirable if a firm requires an innovation to comply with a new or existing government regulation.

Any of the previously described metrics will likely be acceptable to firms, as they all gauge success of a collaboration based on some form of gain by the firm partnering with the academic. However, universities should avoid the out-the-door criterion if they wish to attract technology transfer collaborations with the industrial world. This is the case, since the out-the-door criterion simply measures success of a transfer on whether or not the technology was adopted by a firm. Therefore, the use of this metric would draw skepticism from firms, as it does not take financial returns from an innovation into account at all (Bozeman, 2000).

\section{CHANGING UNIVERSITY MISSION STATEMENTS}

Another reason that technology transfers are not more prevalent from the university to the industrial setting is that many university researchers are mainly interested in performing basic research in order to publish academic papers. This publish first view on the part of academics is partially due to the stated missions of the university laboratories they work in. Studies show that universities with basic research as their main mission are less likely to have academics that participate in technology transfer (Bozeman, 2000).

A change in a universities mission statement could foster more technology transfer on the part of the academics employed by them. The mission statement does not have to deemphasize basic research, as this is obviously one of the most important functions of a research university. It simply should be broadened to include technology transfers. This broadening of the mission statement will likely encourage academics to take a more active role in pursuing and continuing technology transfer efforts (Bozeman, 2000).

\section{EXTRINSIC REWARDS FOR THE ACADEMIC}

The broadening of a mission statement will not cause the necessary changes to enhance technology transfer if there is no linkage between a successful transfer and career advancement for the academic. Universities can link technology transfer with career advancements by granting promotions and allowing technology transfer to count toward tenure (Lee, 1996).

In order for an academic to achieve technology breakthroughs that result in promotions and tenure, a professor must have the necessary financial resources to thoroughly research the topic. Currently universities are receiving insufficient endowments to satisfy an academic's research needs. This lack of funding should encourage academics to partner with a firm to research technology, as the firm could be a source of funding that the academic desperately requires (Chesbrough, 2003, p. 45).

\section{INTRINSIC REWARDS FOR THE ACADEMIC}

The opportunity for an academic to better his/her career and gain funding is only part of the total reward package he/she would receive from a successful transfer of technology. Other than the extrinsic rewards of higher compensation and greater funding through successful technology transfer, non-monetary intrinsic rewards will also be obtained. 
Although intrinsic rewards may appear obvious and the result of common sense, they are often overlooked by academics and universities because of the emphasis placed on monetary gains in society. Despite the fact that they are often overlooked, intrinsic rewards can be a cost effective method to entice an academic to pursue technology transfers if used correctly.

Perhaps the greatest reward for an academic would be the prestige that is associated with technology transfer to a well-known firm. If an academic successfully transfers technology to a leading firm, then he/she will gain respect both from his/her colleagues and also from those in the industry in question for designing cutting edge technology (Geoghengan and Pontikakis, 2008).

The academic would also achieve greater fame through successful technology transfer. Successful technology transfers are sure to be the subject of many industry magazine and journal articles. Therefore, the academic who designs a successful technology to transfer will gain ample exposure in his/her field of study (Geoghengan and Pontikakis, 2008).

Researchers would also intrinsically benefit from witnessing their technologies being used in an industrial setting. A researcher who successfully transfers technology from the university to a firm will likely gain a profound sense of achievement and encouragement to continue their research endeavors. This is because he/she will have the knowledge that their innovations are actually viable in the real world and are more than just theories written in a journal with little real world viability (Geoghengan and Pontikakis, 2008).

\section{DIRECT BUSINESS PARTNERSHIPS BETWEEN UNIVERSITIES AND FIRMS}

Rather than indirectly encouraging technology transfer through changing mission statements and rewarding successful transfer, universities could facilitate technology transfer through direct linkages with industry. This direct link would be formed between a university and industry by encouraging a university to invest part of its endowment as start-up assistance to a firm or make equity investments in a firm (Lee, 1996). This would create a situation where both sides would likely aggressively work with each other to achieve technology transfer, as both sides would achieve financial gains through the transference of technology.

This direct linkage has drawbacks that cause it to lack support in the academic world. The largest drawback is that it would encourage academics to pursue projects that are financially advantageous to the firm and the university. Therefore, it could cause academics to research financially viable but intellectually lacking ideas rather than projects with true intellectual value (Lee, 1996).

Another major reason for lack of support of direct linkages between the academic world and industry stems from the nature of the proprietary technology which would result from the partnerships. Naturally, a firm would prefer any technological breakthroughs which it gains through the partnership remain secret so it can secure a competitive advantage through the technology. The desire of a firm to obtain a competitive advantage through obtaining cutting edge technology would lead to a secrecy agreement stating that the technology discovered not be made public for a set amount of time. This could result in a situation where the academic is unable to publish an article highlighting his/her achievement. Since publishing is a major objective of academics, the possibility of a secrecy agreement would be very detrimental (Lee, 1996).

\section{RECIPROCAL TECHNOLOGY TRANSFER}

If parties cannot or will not agree to terms that will allow for a direct business partnership, then they may want to consider a looser business relationship called reciprocal technology transfer. Reciprocal technology transfer is a recent collaboration method where a university agrees to prepare online training materials for a firm. The firm usually pays for the materials in cash (Sobol and Newell, 2003).

Ample interactions between the academics preparing the firm's materials and employees of the firm occur during the preparation of the materials. These encounters can easily lead to the building of relationships between academics and employees of firms that are conducive to technology transfer. 
Despite the opportunity for technology transfer that these arrangements provide for, they are not universally supported. Opponents of reciprocal technology transfer in the business world cite the concern that academics may need too much time to complete lessons for time sensitive firms. Opponents in the academic world are concerned that academics that complete these projects will fall behind on publishing, as many of the projects undertaken in these arrangements are not conducive to academic article publishing (Sobol and Newell, 2003).

\section{GOVERNMENT SPONSORED PROGRAMS TO FOSTER TECHNOLOGY TRANSFER}

Since direct business partnerships and reciprocal technology transfer agreements between universities and businesses are often unrealistic, universities and firms might wish to consider investigating government operated programs to assist them with their technology transfer efforts. Several government programs were created with technology transfer in mind. Two of the main programs are the Small Business Innovation Research Program (SBIR) and the National Science Foundation (NSF) (Sobol and Newell, 2003).

Founded in 1982, the SBIR is a government operated organization which encourages technology transfer by granting funds to businesses with less than 500 employees. To receive funds, firms must submit a written research proposal to the SBIR. If the proposal is accepted, then monetary contributions are given to the firm. The firm then can use these funds to pay an academic to participate in the researching of the proposed project (Sobol and Newell, 2003).

Resources for SBIR grants are provided by government agencies and donations from private firms. The SBIR is a great method for small businesses to participate in technology transfer for multiple reasons. First, it provides a subsidy for engaging in research through the grants it offers. This will allow collaborations between small businesses and academics that may have never occurred in the programs absence, as many small firms lack the necessary funds to support collaborations with academics. Also, the SBIR is a great way to engage in technology transfer because the firm must create a detailed proposal of the research they wish to perform. This is helpful; as the academic will be able to read the proposal and know from the beginning exactly what the firm requires and expects (Sobol and Newell, 2003).

Although the SBIR is helpful in connecting industry and academics, it has the major drawback that the employer has only 500 employees. Employers who are too large to qualify for SBIR funding should consider the National Science Foundation (NSF) for help in their technology transfer endeavors. The NSF has several programs which link academics with businesses (Sobol and Newell, 2003).

One of the NSF's initiatives is called the Faculty and Students in Industry program. Students and academics from science and engineering fields receive anywhere from $\$ 25,000$ to $\$ 50,000$ for a three to twelve month research collaboration with a firm. Fellowships for graduate level students are also granted so they can work for a period of time in an industry that is related to their field of study (Sobol and Newell, 2003).

Another initiative created by the NSF to enhance technology transfer is the Industry Engineers and Scientists in Academe program. This program endows industry engineers so they can perform collaborative research with academics. It also provides students with funds so they can work in the industry relevant to their curriculum (Sobol and Newell, 2003).

Finally, the NSF offers the Industry-University Collaborative Projects initiative. Grants through this program allow for a longer period of collaboration between an academic and a firm. Grants from this program are provided only if both sides agree to terms on intellectual property rights for their creations. Also, during the last time period of the funding, the firm in question is required to pay at least half of the academic's salary. In exchange, the academics must make a series of visits to the firm's facilities (Sobol and Newell, 2003).

\section{TECHNOLOGY INCUBATORS}

If firms find that no government sponsored initiatives can help them in their quest for technology transfer, they may want to seek out assistance from technology incubators. Technology incubators are created through grants 
from the United States Department of Commerce. They are then jointly maintained by a university and its local Chamber of Commerce (Sobol and Newell, 2003).

Technology incubators have a few general missions which they strive to achieve. First, they attempt to give local businesses and academics the tools and services they need to commercialize their research innovations. Second, the incubator seeks to improve the image of the university that sponsors it by facilitating the transfer of research innovations from the classroom to the marketplace. Finally, technology incubators attempt to improve the surrounding economy by creating businesses through linking interested industrial and academic entrepreneurs (Sobol and Newell, 2003).

Many services are offered by a technology incubator. These services cover most of the basic needs to either establish a firm with the technologies discovered through collaboration or simply market an innovation at an existing company. Services include: marketing and public relations strategy assistance, information about funding sources, directories of professional services (i.e. legal services), office space, internet access, mentoring, etc (Sobol and Newel, 2003).

Any firm or group of entrepreneurs, who wish to partake in the services of a technology incubator, must be admitted into it. To be admitted to an incubator, the party in question must create a detailed business plan and submit it to the technology incubator. The plan must include information such as: reasons the firm/product is commercially viable, the business concept, a financial plan, and how the technology will create jobs for the area. They also must express interest in working in collaboration with academics in the university through the technology incubator. If a business plan is accepted, the technology incubator usually receives a small amount of equity in the firm or product in exchange for access to the services offered by the incubator (Sobol and Newell, 2003).

\section{ENSURING THAT TECHNOLOGY TRANSFER OFFICES ARE EFFECTIVE}

Technology incubators are great resources to facilitate technology transfer. However, they are not found at many universities. Therefore, firms may wish to use a university's Technology Transfer Office (TTO) to aid in technology transfer when technology incubators are absent. TTO's are commonplace at most major universities. TTO's are designed to facilitate the collaboration between firms and academics employed by a university by acting as a liaison. However, if they are not properly maintained and utilized, they will fail to serve their purpose (Siegal, Waldham, Atwater, and Link, 2004).

The first measure to ensure that a TTO is effective is that it is given the necessary budget to meet its needs. Budget is a major problem with TTO's, as surveys of TTO managers uncover that they feel they are not allotted the necessary resources to effectively meet their goals (Geoghegan and Pontikakis, 2008). One major step in ensuring that TTO's receive their necessary allotment is to require the TTO to report to the President of the university (Collier, 2008). If the TTO reports directly to the President of the university, they are more likely to receive the funding they require. This is the case, because the TTO will be able to directly communicate their importance in the university and their need for funding directly to the person who is ultimately responsible for funding allotment in a university.

A sizable portion of the budget of a TTO is spent on staffing it effectively. TTO staffing is a problem as research revealed that many TTO managers describe their own staff as unprofessional and inexperienced. Measures must be taken to staff TTO's more effectively to correct this apparent problem (Geoghegan and Pontikakis, 2008).

When staffing TTO's, workers who bring certain skill sets to the table may help to make the TTO more effective. For instance, a TTO should strive to hire employees who possess marketing experience and skills, because TTO's that employ people with marketing backgrounds tend to be more effective at creating links between firms and academics. Also, TTO's should strive to hire professionals with negotiation experience, because TTO's who employ people with this skill tend to be more successful at creating technology transfer partnerships (Siegal et al, 2004).

Apart from staffing and budget requirements that must be satisfied, there are several practices that TTOs should partake in to enhance their role as an effective agent of transfer. One initiative that will likely enhance their 
effectiveness is to establish an entrepreneur in residence program. This will facilitate technology transfer, as it will create direct linkages between the business and academic world within the university system (Collier, 2008).

TTO offices also can become more effective in creating collaborations by sponsoring events such as affiliations, consortia, and conferences. These three events can easily create technology transferring relationships between academics and industry, as they bring together the two groups to discuss issues that they mutually find important (Collier, 2008).

\section{CREATING INDUSTRY SPECIFIC RESEARCH INSTITUTES TO FOSTER TRANSFER}

A creation that could foster technology transfer that would not require universities to make any changes is the establishment of industry specific research institutes to help foster technology transfers. One such agency that was created to foster technology transfer is the Electrical Power Research Institute (EPRI). This agency has been facilitating technology transfer since 1973, and its components can be adapted to create research institutes for other industries (EPRI, 2009).

EPRI is a nonprofit organization, which is dedicated to solving a wide variety of issues in the electric industry. The organization sponsors and commissions research conducted by companies and academics. Research projects are monitored and facilitated by a Board of Directors, made up of industry experts (EPRI, 2009).

EPRI also has specific departments, such as the Office of Innovation, which is dedicated to meeting certain organizational goals. Furthermore, the organization also sponsors many seminars on a wide variety of industry related topics. These seminars are a perfect way for academics and industry insiders to meet face to face and talk about industry needs and academic developments (EPRI, 2009).

\section{BUILDING RELATIONSHIPS WHICH FOSTER TECHNOLOGY TRANSFERS}

In reviewing the above, a common theme should be apparent in most of the recommendations to help bolster technology transfer. That theme is the building of relationships. Whether it is through a technology incubator or a business partnership between a university and a firm, relationships need to be built and maintained to ensure that technology transfer occurs.

These relationships must be given time to mature to ensure successful technology transfer. Therefore, oneyear research arrangements between a professor and a firm, which are commonplace in today's business environment, are an insufficient amount of time to truly take advantage of technology transfer (Foley, 1996).

When forming long term relationships that lead to transfer of technology, several key components should be present during the communications between the academic and the industry professional. These components will increase the likelihood that successful technology transfers occur. One such component is that both parties must continually share a vision of the possible benefits of the technology transfer. If both parties continually share with each other the envisioned benefit of the end result of the transfer, then both parties are more likely to continue on with the research until completion (Bennett, 1996).

Another component that must be present in the relationship is a mutual trust and understanding of the other party's perspective on technology. Problems can arise because academics tend to view research on technologies in the long-term while industry professionals view it in the short term. For example, an academic may not care how long it takes him/her to design a new technology, as long as the finished product results in a published academic article. On the other hand, industry professionals tend to view technology research in the short-term. Usually they want technology to be finished as soon as possible so their firm can profit from the innovation. Both parties must realize that the other views research in a different light and make compromises to ensure that neither side becomes frustrated by the other's view (Bennett, 1996).

Even if both sides of the relationship understand each other, technology transfer will be unlikely to occur unless the academic continuously shares the knowledge that he/she has recently uncovered with the industry 
professional he/she is partnering with. The academic can achieve this by periodically scheduling a meeting with personnel from the firm in question that have a stake in the technology. This meeting will benefit both sides and ensure continued support for the project because it will show the firm where the research is headed and will allow employee's from the firm to give the academic advice as to how his/her research can be tweaked to better serve the firm's needs (Bennett, 1996).

As mentioned above, academics tend to view research in the long term and need multiple years of partnerships with a firm to achieve their desired technological innovation. Multiple years of partnerships are also needed to gain the trust and open communications needed for a firm to truly buy-in to an innovation made by an academic (Foley, 1996).

One such buy-in that is vital but often overlooked is the support of a firm's top management. Without the support of top-management, there is little chance for technology transfer, because the necessary time and funds will not be given to support such a transfer. Therefore, academics should build relationships with top management (Foley, 1996).

Another relationship that is often overlooked but is a powerful tool to help transfer technology concerns the student. When students, who are research assistants for a professor working on a project for a company gain employment at the company in question, technology transfer is more readily achieved. Technology transfer is more likely to occur because the student already has first-hand knowledge of the technology being designed and has a relationship with the designer. Therefore, the student will continue this relationship after placement to foster continued communication about the technology design in question and ensure that the design is actually adopted by the firm (Foley, 1996).

Multiple years of patterning are also necessary for academics to gain a nuanced understanding of exactly the kind of technology that is necessary for use in the industry for which it is being designed. For instance, some technologies are theoretically superior to ones that are currently in use, but they may not be practical for firm's to adopt for various reasons. Therefore, an academic should take the time to learn about an industry's product development cycle to ensure that his/her technology innovation is practical to adopt. This knowledge is only obtained through a long period of partnership between an academic and a firm (Foley, 1996).

\section{HOW BUSINESSES CAN BUILD RELATIONSHIPS THAT SUPPORT TECHNOLOGY TRANSFER}

Since mutual understanding and fairly long periods of time are needed for successful technology transfer, businesses should make earnest attempts to build the necessary relationships to successfully harness technology transfer. There are several methods that a firm can use to build such a relationship with an academic.

The most costly, but perhaps the most effective, method to establish a relationship between a firm and an academic would be for a firm to contribute funds to a university's research budget in exchange for a first cut at resulting technologies. This would likely create a strong relationship, as the academic would now rely partially on the firm for funding and the firm has invested substantial funds in order to achieve some sort of technological advantage. Therefore, both sides would likely bond and work together to ensure that the other is satisfied with the relationship (Chesbrough, 2003, p. 194).

If donating funds to a university is too costly for a firm, then they may try to create a relationship through the donation of equipment from a firm's Research and Development office to an academic. Besides creating a bond between the firm and the academic recipient, which could lead to future communication and possible technology transfer, donated equipment will also lead to benefits for both the academic and the firm.

Obviously, the equipment will help a resource strapped academic, as he/she will be able to obtain high tech equipment without spending any of his/her research stipend. It will also help a firm. Since the academic will learn how to use the equipment, he/she can train new workers at the firm on how to use the equipment in the future. Also, a firm should keep up to date on how an academic uses the donated technology. Competitive advantages could be gained by a firm if they are informed of more effective methods of using their existing technology (Chesbrough, 2003, p. 188). 
If a firm is unable or unwilling to donate equipment to an academic, relationships can also be established with an academic indirectly through granting scholarships to promising graduate students. After a graduate student has been given a scholarship from a firm, the firm should communicate with the student about the research being performed by professors he/she works with and studies under. The students can then act as a conduit and help connect professors with firms that are interested in a particular professor's research endeavors (Chesbrough, 2003, p. 190).

Even if a firm is strapped for funds and is unable to donate research funds to a professor or student, relationships can still be established. One of the easiest ways to establish a relationship would be for a firm to invite a professor to a firm for a tour of their facilities. During the tour both parties can speak about their research efforts and desires. After this session, both sides may know enough about the other to determine if they want to establish a more in-depth relationship, which is necessary for technology transfer (Chesbrough, 2003, p. 190).

\section{CONCLUSION}

Business leaders and academics are hesitant to engage in technology transfer because of perceptions of the other party involved and fear that technology transfer will not lead to a successful outcome. There are many methods that can be used to reassure reluctant business leaders and academics that technology transfer is mutually beneficial.

Metrics should be used to reassure the business community that the academic is aware that the technology being developed is beneficial to them. Market impact and economic impact criteria can be used to gauge the positive economic benefits of a technological development. Political effectiveness criteria should be used if a company wishes to achieve compliance with government mandates.

Universities can make policy changes to encourage technology transfers on their own. Changing mission statements to include technology transfers as an objective can help change the mindset of the basic "research first" academics that they employ. Along with the change in mission statement, universities should consider successful technology transfer as a component of gaining promotions and tenure. Also, universities should stress the intrinsic and extrinsic rewards of successful technology transfer to their faculty.

Firms and universities can encourage technology transfer through direct business partnerships. However, these partnerships can harm the research potential of universities. So, looser relationships between universities and businesses are often pursued.

Reciprocal technology transfer is a new method that companies and universities are using to pursue technology transfer. However, some academics are hesitant to pursue these relationships because such an agreement may hinder their publishing efforts.

Government programs such as the SBIR and the NSF help companies and individuals to engage in technology transfer. However, certain restrictions and criteria have to be considered when companies and universities enter into these programs.

Technology incubators help give academics and universities the tools to successfully collaborate. However, they are absent from many universities. Technology transfer offices can help firms and academics develop new technologies. However, universities must ensure that they are properly staffed and are pursuing policies that are conducive to technology transfer.

Research institutes are organizations that are built independently of universities and businesses. Despite their independent status, they can bring both sides together by creating programs that encourage industry and academics to collaborate.

Even with organizations to help the collaboration process, technology transfer is unlikely to occur if the participants involved fail to reach a mutual understanding and respect for the others endeavors. Long term relationships built on open communication are necessary to achieve this mutual understanding. Also, each side must communicate their requirements and desired outcomes for the project being pursued. 
Firms can help build this open relationship through a number of methods. They can donate funds and equipment to academics, instantly creating a close bond. If this is not possible, then they can create a bond by granting scholarships to promising students who can act as a liaison between them and the academic. Finally, firms can establish relationships without spending any money by simply inviting the academic for a tour of their facilities.

This research paper has highlighted methods that can be used to encourage industry-academic collaborations. Although all these methods can successfully lead to technology transfer, the choice of method to use has to be determined by the firm and university in question based on their circumstances. Therefore, universities and firms should consider all the above options and pursue the ones that are most appropriate for their needs. As mentioned earlier, the technology transfer discussion included in this research paper is applicable to a wide variety of industries, including the energy industry, which is of particular interest to the author.

\section{AUTHOR INFORMATION}

Dr. Fuller is a Professor of Decision Analysis and Operations Management in the College of Business and Economics at West Virginia University. His degrees include a Bachelors of Science in Electrical Engineering from Iowa State University, a Masters of Arts in Quantitative Methods from the University of Iowa, and a Doctor of Philosophy in Business Administration with a major in Operations Management from the University of Arkansas.

Dr. Fuller's research and teaching interests include the application of analytical and economic models to various types of businesses. In recent years, his research has focused on energy policy and operational issues. He has had 36 research articles published in refereed journals, made 87 research presentations to professional and academic conferences, and received six best paper awards for research presentations at academic conferences.

Christopher Hohman graduated from West Virginia University in 2009 with an M.S. Industrial Relations degree. Before that, he graduated Phi Beta Kappa from Penn State University with a B.A. in Political Science. At Penn State University, he worked as a research assistant in the Political Science department. He worked as a technical writer producing standard operating procedures and training modules for manufacturing processes at TRACO, a window and door company near Pittsburgh, PA. More recently, he has worked in Compensation for General Nutrition Centers in Pittsburgh, PA.

\section{REFERENCES}

1. Bennett, J. (1996). Building relationships for technology transfer. Communications of the ACM, 29(9),35-36.

2. Bozeman, B. (2000). Technology transfer and public policy: A review of research and theory. Research Policy, 29, 627-655.

3. Chesbrough, H. (2003) Open innovation: the new imperative for creating and profiting from technology. Boston, Massachusetts: Harvard Business School Press.

4. Collier, A. (2008). Indentifying superior performance factors relevant to Australian university TTOs. Comparative Technology Transfer and Society, 6 (2), 61-87.

5. Electric Power Research Institute (EPRI). (2009). About EPRI. Retrieved June 23, 2009, from http://my.epri.com/portal $/$ server.pt?open $=512 \&$ objID=200\&mode $=2 \&$ in hi userid $=2 \&$ cached $=$ true

6. Foley, J. (1996). Technology transfer from university to industry. Communications of the ACM, 29(9),30-31.

7. Geoghegan, W. and D Pontikakis. (2008). From ivory tower to factory floor? How universities are changing to meet the needs of industry. Science and Public Policy, 35 (7), 462-474.

8. Lee, Y. (1996). 'Technology transfer' and the research university: a search for the boundaries of universityindustry collaboration. Research Policy, 25, 843-863.

9. Reisman, A. (2004). Transfer of technologies: a cross-disciplinary taxonomy. Omega,33 (3), 189-202.

10. Siegal, D., Waldham, D., Atwater, L., and Link, A. (2004). Toward a model of effective transfer of scientific knowledge from academicians to practitioners: qualitative evidence from the commercialization of university technologies. Journal of Engineering Technology and Management, 21, 115-142.

11. Sobol, M. and M. Newell. (2003). Barriers to and measurements of the diffusion of technology from the university to industry. Comparative Technology Transfer and Society, 1 (3), 255-278. 